\title{
Effect of severe acidosis on vasoactive effects of epinephrine and norepinephrine in human distal mammary artery
}

\author{
Charles Vidal, MD, ${ }^{\mathrm{a}, \mathrm{b}}$ Stanislas Grassin-Delyle, PharmD, ${ }^{\mathrm{a}}$ Philippe Devillier, $\mathrm{MD}, \mathrm{PhD},{ }^{\mathrm{a}}$ \\ Emmanuel Naline, PharmD, ${ }^{\mathrm{a}}$ Emmanuel Lansac, MD, ${ }^{\mathrm{c}}$ Philippe Ménasché, MD, PhD, ${ }^{\mathrm{d}}$ and \\ Christophe Faisy, MD, $\mathrm{PhD}^{\mathrm{a}, \mathrm{b}}$
}

\begin{abstract}
Objective: Acidosis is a very common pathologic process in perioperative management. However, how to correct severe acidosis to improve the efficacy of vasoconstrictors in hemodynamically unstable patients is still debated. The present study investigated whether severe extracellular acidosis influences the vasoactive properties of vasoconstrictors on human isolated arteries.
\end{abstract}

\begin{abstract}
Methods: Segments of intact distal internal mammary arteries were removed from 41 patients undergoing artery bypass grafting. The arterial rings were washed in Krebs-Henseleit solution and suspended in an organ bath. The rings were set at a pretension equivalent of $100 \mathrm{~mm} \mathrm{Hg}$, and the relaxation response to $10 \mu \mathrm{M}$ acetylcholine was verified. Concentration-response curves for epinephrine, norepinephrine, methoxamine $\left(\alpha_{1 \mathrm{~A} / \mathrm{D}}\right.$-adrenoceptor agonist), phenylephrine (equipotent agonist of $\alpha_{1 \mathrm{~A} / \mathrm{B}}$-adrenoceptors), and clonidine ( $\alpha_{2}$-adrenoceptor agonist) were achieved under control conditions ( $\mathrm{pH}$ 7.40) and under acidic conditions by substitution of the Krebs-Henseleit solution with a modified solution.
\end{abstract}

Results: Decreasing the $\mathrm{pH}$ from 7.40 to $7.20,7.0$, or 6.80 did not significantly alter the potency and efficacy of epinephrine and norepinephrine, although the standardized effect size was sometimes large. Severe acidosis (pH 6.80) did not significantly change the potency and efficacy of phenylephrine and clonidine, although it increased the efficacy and potency of methoxamine $(P<.001$ and $P=.04$ vs paired control conditions, respectively).

Conclusions: Extracellular acidosis did not impair the vasoactive properties of epinephrine and norepinephrine in human medium-size arteries until $\mathrm{pH}$ 6.80. The results of the present study also suggest that acidosis might potentiate arterial responsiveness to vasoconstrictors, mostly by way of the $\alpha_{1 \mathrm{D}}$-adrenoceptor. (J Thorac Cardiovasc Surg 2014;147:1698-705)

Epinephrine or norepinephrine should be initiated to restore arterial pressure and organ perfusion in hemodynamically unstable patients, especially during perioperative management. ${ }^{1}$ Epinephrine and norepinephrine act mainly through the $\alpha_{1} / \alpha_{2}$-adrenoceptors, increasing the intracellular calcium concentration in the vascular smooth muscle cells. ${ }^{2}$ Unlike

From the Research Unit UPRES EA220, ${ }^{\mathrm{a}}$ Versailles Saint-Quentin-en-Yvelines University, Hôpital Foch, Suresnes, France; Medical Intensive Care Unit, ${ }^{\mathrm{b}}$ Hôpital Européen Georges Pompidou, Assistance Publique-Hôpitaux de Paris, University Paris Descartes, Sorbonne Paris Cité, Paris, France; Department of Cardiovascular Surgery, ${ }^{\mathrm{c}}$ Institut Mutualiste Montsouris, Paris, France; and Department of Cardiovascular Surgery, ${ }^{\mathrm{d}}$ Hôpital Européen Georges Pompidou, Assistance Publique-Hôpitaux de Paris, Université Paris Descartes, Sorbonne Paris Cité, Paris, France.

The present study was supported by Research Unit UPRES EA220 and the Medical Intensive Care Unit, Hôpital Européen Georges Pompidou and not by any financial grant.

Disclosures: Authors have nothing to disclose with regard to commercial support.

Received for publication June 7, 2013; revisions received Oct 17, 2013; accepted for publication Nov 8, 2013; available ahead of print Dec 11, 2013.

Address for reprints: Christophe Faisy, MD, PhD, Medical Intensive Care Unit, Hôpital Européen Georges Pompidou, Assistance Publique-Hôpitaux de Paris, University Paris Descartes, 20-40 rue Leblanc, Paris 75908 Cedex, France (E-mail: christophe.faisy@egp.aphp.fr).

0022-5223/\$36.00

Copyright (c) 2014 by The American Association for Thoracic Surgery

http://dx.doi.org/10.1016/j.jtcvs.2013.11.013 norepinephrine, epinephrine can restore blood pressure by way of the cardiac $\beta_{1}$-adrenoceptors. The $\beta$-adrenergic effects of epinephrine are marked at low doses and $\alpha_{1}$-adrenergic effects at higher doses. Epinephrine enhances coronary blood flow by an increased duration of diastole, which counterbalances the $\alpha_{1}$-mediated coronary vasoconstriction. ${ }^{3}$ Epinephrine has been used for cardiac arrest and as a second-line treatment of isovolemic shock resistant to dobutamine or in the case of refractory septic shock. Norepinephrine is mainly an $\alpha_{1}$-adrenergic receptor agonist with slight $\beta$-agonist activity. Norepinephrine increases the systolic and diastolic blood pressure and has a minimal effect on cardiac output. ${ }^{3}$ Norepinephrine has commonly been used as a first-line treatment for isovolemic septic shock.

The effects of acidosis on the cardiovascular system have been investigated, especially in left ventricular depressant dysfunction and systemic vasodilatation. ${ }^{2,4}$ Acidosis can also promote the development of severe ventricular arrhythmia after reperfusion for myocardial infarction. ${ }^{5}$ However, the influence of acidosis on the efficacy of vasopressor agents is still debated, although severe acidosis $(\mathrm{pH}<7.10)$ can be viewed as an indication for hemofiltration in patients with shock. ${ }^{6}$ Moreover, the use of bicarbonate to treat severe metabolic acidosis has been challenged in 


\section{Abbreviations and Acronyms \\ $\mathrm{CI}=$ confidence interval \\ $d=$ standardized effect size}

humans; however, no study has demonstrated a benefit in terms of hemodynamic improvement. ${ }^{7-9}$ Chronic diseases of the circulatory system could also affect the efficacy of vasoconstrictors in critically ill patients. Few studies have investigated the effects of severe acidosis on the vasoactive properties of vasoconstrictors from fresh complete human tissues. Intact fresh resistance microvessels (internal diameter $<200 \mu \mathrm{m})$ are more difficult to obtain from humans than intact conductance vessels (internal diameter $>500 \mu \mathrm{m}$ ). However, the internal mammary artery, the graft of choice for myocardial revascularization, is more easily obtainable, and the distal internal mammary artery is pharmacologically responsive to vasoconstrictors. The present study investigated whether severe extracellular acidosis influences the vasoconstriction induced by epinephrine and norepinephrine on distal segments of human isolated internal mammary arteries.

\section{METHODS}

\section{Tissue Preparations}

Our local ethics committee (Comité de Protection des Personnes se Prêtant à la Recherche Biomédicale Ile de France VIII, France) approved the present study, and patients gave informed consent before their scheduled surgery. Internal mammary arteries were obtained from 41 patients (34 men and 7 women; mean age, $65 \pm 11$ years) undergoing artery bypass grafting in 2 cardiovascular surgery departments in Paris. All vasoactive medications were suspended the evening before the surgical procedure. Excised segments of the distal arteries were immediately immersed and washed thoroughly in oxygenated Krebs-Henseleit solution $(\mathrm{NaCl} 119$ $\mathrm{mM}, \mathrm{KCl} 4.7 \mathrm{mM}, \mathrm{CaCl}_{2} 2.5 \mathrm{mM}, \mathrm{KH}_{2} \mathrm{PO}_{4} 1.2 \mathrm{mM}, \mathrm{NaHCO}_{3} 29 \mathrm{mM}$, and glucose $11.7 \mathrm{mM}$ ) to remove any intraoperative drug residue. The tissues were maintained at $4{ }^{\circ} \mathrm{C}$ and transported to the laboratory as soon as possible. After removal of the adhering connective tissues, the rings of tissue were prepared and suspended on hooks in a $5-\mathrm{mL}$ organ bath containing Krebs-Henseleit solution, gassed with $95 \%$ oxygen and $5 \%$ carbon dioxide $(\mathrm{pH} 7.40)$, and maintained at $37^{\circ} \mathrm{C}$. Each preparation was connected to a force displacement transducer, and the isometric tension changes were recorded and postprocessed with iox 2 and datanalyst software (EMKATechnologies, Paris, France). The arterial rings were set at a pretension equivalent of $100 \mathrm{~mm} \mathrm{Hg}$, calculated from the internal circumference and the wall tension derived from the Laplace law. ${ }^{10,11}$

\section{Experimental Protocol}

The arterial rings were washed again and equilibrated for $\geq 60$ minutes

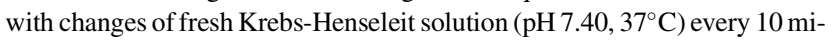
nutes during the first 30 minutes of the initial equilibration period. The rings were then challenged by the addition of $90 \mathrm{mM} \mathrm{KCl}$, which stimulates the voltage-dependent $\mathrm{Ca}^{2+}$ channels, to stabilize the preparations and ensure reproducible contractile responsiveness, as previously reported. ${ }^{12}$ The functional integrity of the endothelium was then verified by the relaxation response $(\geq 20 \%)$ to $10 \mu \mathrm{M}$ acetylcholine. The baseline tension was restored by washing the rings 4 times with Krebs-Henseleit solution. The addition of epinephrine or norepinephrine, $2 \alpha_{1^{-}}$and $\alpha_{2}$-subtype, nonselective adrenoceptor agonists, in the organ bath was randomly determined for each arterial ring, limiting the selection bias. Concentration-response curves were constructed for epinephrine $\left(10^{-9}\right.$ to $\left.3.10^{-5} \mathrm{M}\right)$ and norepinephrine $\left(10^{-9}\right.$ to $\left.10^{-4} \mathrm{M}\right)$ by applying increasing concentrations, at 5-minute intervals, under standard conditions $\left(\mathrm{pH} 7.40,37^{\circ} \mathrm{C}\right)$. After washing and restabilization, the $\mathrm{pH}$ was decreased in the organ bath from 7.40 to $7.20,7.0$, or 6.80 by substitution of Krebs-Henseleit solution with a modified solution $\left(\mathrm{NaHCO}_{3}, 23,17\right.$, or $11 \mathrm{mM}$, respectively). After equilibration in the $\mathrm{pH}-$ modified solution for 20 minutes, the concentration-response curves were obtained again under acidic conditions, with each ring serving as its own control. In the preliminary experiments, reversing the standard and acidic conditions in the organ bath did not influence the contraction elicited by epinephrine or norepinephrine (data not shown).

\section{Pharmacologic Interventions}

To investigate the effect of acidosis on the $\alpha$-adrenoceptor subtypes, a second set of experiments was performed according to the same experimental protocol using an $\alpha_{1 \mathrm{~A} / \mathrm{D}^{-}}$adrenoceptor agonist $\left(10^{-9}\right.$ to $10^{-4}$ $\mathrm{M}$ methoxamine), an equipotent agonist of $\alpha_{1 \mathrm{~A} / \mathrm{B}}$-adrenoceptor $\left(10^{-9}\right.$ to $3.10^{-5} \mathrm{M}$ phenylephrine) and a peripheral $\alpha_{2}$-adrenoceptor agonist $\left(10^{-9}\right.$ to $10^{-4} \mathrm{M}$ clonidine).

\section{Drugs}

Epinephrine came from Aguettant (Lyon, France). Norepinephrine was purchased from Renaudin (Itxassou, France). Methoxamine, phenylephrine, clonidine, and acetylcholine were purchased from Sigma-Aldrich (St Louis, Mo). $\mathrm{KCl}$ was purchased from B-Braun (Melsungen, France). All drugs were dissolved in distilled water and then diluted in KrebsHenseleit solution. The final amount of distilled water in the organ bath was negligible.

\section{Statistical Analysis}

The data are presented as the mean \pm standard deviation. The results were analyzed using the Wilcoxon signed rank test, and differences within the standard curves were analyzed using 1-way repeated measures analysis of variance, with Bonferroni adjustments for multiple comparisons, when required (StatView, version 5.0; SAS Institute, Cary, NC). Because inadequate statistical power could not be ruled out, the standardized effect size, $d$, for the difference between the mean values was calculated to determine whether the observed effect of acidosis was small $(|d| \geq 0.20)$, medium $(|d|$ $\geq 0.50)$, or large $(|d| \geq 0.80)$, according to the Cohen conventions. ${ }^{13}$ The $95 \%$ confidence interval (CI) for $d$ was calculated to determine the uncertainty around the real effect of acidosis. The basal tone was expressed in tension $(g)$, measured just before the addition of drugs in the organ bath. Changes in the arterial ring tone are expressed in tension $(g)$ and the percentage of the maximal contraction induced by $90 \mathrm{mM} \mathrm{KCl}$ under standard conditions, because acidosis had significantly decreased the maximal contraction induced by $90 \mathrm{mM} \mathrm{KCl}$ in the preliminary experiments $(1.69$ $\pm 0.42 \mathrm{~g}$ at $\mathrm{pH} 6.80 \mathrm{vs} 2.96 \pm 0.5 \mathrm{~g}$ at $\mathrm{pH} 7.40 ; \mathrm{n}=11 ; P<.001)$. The efficacy of the agonist corresponded to the change in the arterial ring tone obtained with the highest agonist concentration tested. The potency of the agonists was defined as the negative logarithm of the molar concentration of the agonist producing $50 \%$ of the maximal effect and was calculated from the concentration-response curves. Arterial rings with contraction induced by $90 \mathrm{mM} \mathrm{KCl}<1 \mathrm{~g}$ or with an absence of relaxation to acetylcholine were excluded from the analysis, because the response was considered a reliable dysfunction marker.

\section{RESULTS}

\section{Sample}

A total of 57 arterial rings were tested, and 47 rings were functional and eligible for analysis. 
TABLE 1. Effects of extracellular acidosis on human arterial basal tone and responsiveness to epinephrine and norepinephrine

\begin{tabular}{|c|c|c|c|c|c|}
\hline \multirow[b]{2}{*}{ pH conditions } & \multirow[b]{2}{*}{$\mathbf{n}$} & \multicolumn{2}{|c|}{ Epinephrine } & \multicolumn{2}{|c|}{ Norepinephrine } \\
\hline & & Measurement & $d(95 \% \mathbf{C I})$ & Measurement & $d(95 \% \mathrm{CI})$ \\
\hline \multicolumn{6}{|l|}{ Basal tone $(\mathrm{g})$} \\
\hline 7.20 & 11 & $1.61 \pm 0.20$ & $-0.33(-0.51$ to 1.18$)$ & $1.33 \pm 0.19$ & $-0.69(-1.55$ to 0.17$)$ \\
\hline 7.40 & & $1.67 \pm 0.14$ & & $1.47 \pm 0.20$ & \\
\hline 7.0 & 10 & $1.70 \pm 0.22$ & $-0.30(-1.18$ to 0.58$)$ & $1.75 \pm 0.10$ & $-0.82(-1.73$ to 0.10$)$ \\
\hline 7.40 & & $1.77 \pm 0.23$ & & $1.89 \pm 0.21$ & \\
\hline 6.80 & 11 & $1.90 \pm 0.27$ & $-0.73(-1.59$ to 0.14$)$ & $1.56 \pm 0.13$ & $-0.95(-1.83$ to 0.07$)$ \\
\hline 7.40 & & $2.10 \pm 0.26$ & & $1.67 \pm 0.09$ & \\
\hline \multicolumn{6}{|l|}{$\mathrm{E}_{\max }(\mathrm{g})$} \\
\hline 7.20 & 11 & $4.59 \pm 0.40$ & $0.23(-0.61$ to 1.07$)$ & $3.89 \pm 0.37$ & $-0.05(-0.89$ to 0.78$)$ \\
\hline 7.40 & & $4.48 \pm 0.52$ & & $3.91 \pm 0.36$ & \\
\hline 7.0 & 10 & $5.56 \pm 0.76$ & $-0.02(-0.90$ to 0.85$)$ & $5.49 \pm 0.82$ & $0.29(-0.59$ to 1.17$)$ \\
\hline 7.40 & & $5.58 \pm 0.81$ & & $5.24 \pm 0.83$ & \\
\hline 6.80 & 11 & $4.79 \pm 0.47$ & $-0.08(-0.92$ to 0.75$)$ & $3.57 \pm 0.26$ & $0.61(-0.25$ to 1.46$)$ \\
\hline 7.40 & & $4.83 \pm 0.46$ & & $3.40 \pm 0.28$ & \\
\hline \multicolumn{6}{|l|}{$\mathrm{pD}_{2}$ (log unit) } \\
\hline 7.20 & 11 & $7.34 \pm 0.31$ & $0.37(-0.47$ to 1.21$)$ & $6.52 \pm 0.28$ & $0.62(-0.24$ to 1.47$)$ \\
\hline 7.40 & & $7.23 \pm 0.26$ & & $6.35 \pm 0.25$ & \\
\hline 7.0 & 10 & $6.73 \pm 0.17$ & $0.48(-0.41$ to 1.37$)$ & $6.31 \pm 0.20$ & $0.09(-0.78$ to 0.97$)$ \\
\hline 7.40 & & $6.66 \pm 0.10$ & & $6.29 \pm 0.21$ & \\
\hline 6.80 & 11 & $7.48 \pm 0.15$ & $0.80(-0.08$ to 1.65$)$ & $6.56 \pm 0.10$ & $-0.91(-1.79$ to 0.03$)$ \\
\hline 7.40 & & $7.34 \pm 0.19$ & & $6.71 \pm 0.20$ & \\
\hline
\end{tabular}

Data presented as mean \pm standard deviation, $d$, and $95 \%$ CI for the difference between the mean values. The observed effect of acidosis was small ( $|d| \geq 0.20)$, medium $(|d| \geq$ $0.50)$, or large $(|d| \geq 0.80)$ according to the Cohen convention. ${ }^{13}$ The $95 \% \mathrm{CI}$ for $d$ consisted of the uncertainty around the real effect of acidosis. The basal tone was measured just before the addition of the vasoconstrictor in the organ bath. Efficacy of agonist corresponded to the change in arterial tone $(g)$ obtained with the highest agonist concentration tested. $\mathrm{pD}_{2}$ of the agonists defined as the negative logarithm of the molar concentration of the agonist producing $50 \%$ of the maximal effect and was calculated from the concentration-response curves (Figure 1, $A, C$, and $E$ ). Each experiment served as its own control. No difference between acidosis and the standard condition (pH 7.40) was statistically significant $(P>.05)$. $d$, Standardized effect size; $C I$, confidence interval; $p D_{2}$, potency; $E_{\text {max }}$, efficacy.

\section{Effect of Extracellular Acidosis on Arterial Basal Tone}

Acidosis did not significantly change the basal tone of the arterial rings in the organ bath except at a low $\mathrm{pH}$ level (6.80), at which acidosis increased the arterial basal tone (Tables 1 and 2). As indicated by the standardized effect sizes, the observed effect of acidosis on basal tone was often medium or large, but the $95 \%$ CI revealed great uncertainty, limiting the conclusions that could be drawn about the real effect of acidosis on the basal tone.

\section{Effect of Extracellular Acidosis on Contraction Induced by Epinephrine and Norepinephrine}

Acidification of the organ bath to a $\mathrm{pH}$ of $6.80 \mathrm{did}$ not significantly alter the efficacy and potency of epinephrine and norepinephrine in the human distal internal mammary artery (Table 1, Figures 1 and 2). The standardized effect sizes showed that the observed effect of acidosis on the efficacy of epinephrine and norepinephrine was small, but the $95 \%$ CI indicated continued uncertainty (Table 1). In contrast, the effect of severe acidosis (pH 6.80) on the potency of epinephrine and norepinephrine was large, as shown by the standardized effect sizes. The uncertainty around the real effect was moderate, suggesting severe acidosis might increase the potency of epinephrine and decrease the potency of norepinephrine (Table 1).

\section{Effect of Extracellular Acidosis on Contractions Induced by Methoxamine, Phenylephrine, and Clonidine}

We set the lower $\mathrm{pH}$ at 6.80 to test methoxamine, phenylephrine, and clonidine, because of the limited availability of tissues and because no significant changes in the basal tone and responsiveness were observed until a $\mathrm{pH}$ of 7.0. Acidification of the organ bath from 7.40 to 6.80 sensitized the arterial rings to methoxamine but did not significantly change their responsiveness to phenylephrine and clonidine (Table 2 and Figure 3). As shown by the standardized effect size and its $95 \% \mathrm{CI}$, the effect of severe acidosis on the efficacy and potency of methoxamine was powerful (Table 2).

\section{DISCUSSION}

The results of the present study have demonstrated that severe extracellular acidosis does not alter the contraction of human distal internal mammary artery induced by epinephrine and norepinephrine, which act by way of the $\alpha_{1 \mathrm{~B}^{-}}$and $\alpha_{1 \mathrm{~A}^{-}}$-adrenoceptors. In contrast, acidosis increased the potency and efficacy of methoxamine, an $\alpha_{1 \mathrm{~A} / \mathrm{D}^{-}}$-adrenoceptor agonist. ${ }^{14,15}$ Moreover, acidosis did not significantly influence the contractile response mediated by clonidine, a peripheral $\alpha_{2}$-adrenoceptor agonist, or by phenylephrine, an $\alpha_{1}$ subtype, nonselective agonist. ${ }^{16}$ Overall, these results have also suggested that severe acidosis might modulate 
TABLE 2. Effect of severe extracellular acidosis (pH 6.80) on human arterial basal tone and responsiveness to methoxamine, phenylephrine, and clonidine

\begin{tabular}{|c|c|c|c|c|}
\hline Measurement & $\mathbf{n}$ & pH 7.40 & pH 6.80 & $d(95 \% \mathrm{CI})$ \\
\hline \multicolumn{5}{|l|}{ Basal tone $(\mathrm{g})$} \\
\hline Methoxamine & 10 & $1.64 \pm 0.14$ & $2.18 \pm 0.28^{*}$ & 2.34 (1.20 to 3.47$)$ \\
\hline Phenylephrine & 10 & $1.85 \pm 0.23$ & $1.88 \pm 0.32$ & $0.10(-0.77$ to 0.88$)$ \\
\hline Clonidine & 5 & $2.10 \pm 0.32$ & $2.84 \pm 0.49^{*}$ & $1.61(0.19$ to 3.04$)$ \\
\hline \multicolumn{5}{|l|}{$\mathrm{E}_{\max }(\mathrm{g})$} \\
\hline Methoxamine & 10 & $3.73 \pm 0.40$ & $4.80 \pm 0.41 \dagger$ & $2.53(1.35$ to 3.71$)$ \\
\hline Phenylephrine & 10 & $5.11 \pm 0.60$ & $5.43 \pm 0.59$ & $0.52(-0.38$ to 1.41$)$ \\
\hline Clonidine & 5 & $3.89 \pm 0.41$ & $4.26 \pm 0.34$ & $0.89(-0.41$ to 2.19$)$ \\
\hline \multicolumn{5}{|l|}{$\mathrm{pD}_{2}$ (log unit) } \\
\hline Methoxamine & 10 & $5.28 \pm 0.11$ & $5.54 \pm 0.10^{*}$ & $2.37(1.23$ to 3.51$)$ \\
\hline Phenylephrine & 10 & $6.93 \pm 0.17$ & $6.66 \pm 0.24$ & $-1.24(-2.20$ to -0.29$)$ \\
\hline Clonidine & 5 & $6.32 \pm 0.31$ & $6.17 \pm 0.20$ & $-0.52(-1.78$ to 0.74$)$ \\
\hline
\end{tabular}

Data presented as mean \pm standard deviation, $d$, and $95 \%$ CI for the difference between the mean values. The observed effect of acidosis was small $(|d| \geq 0.20)$, medium $(|d| \geq$ $0.50)$, or large $(|d| \geq 0.80)$ according to the Cohen convention. ${ }^{13}$ The $95 \%$ CI for $d$ consisted of the uncertainty around the real effect of acidosis. $\mathrm{E}_{\text {max }}$ corresponded to change in arterial tone (g) obtained with the highest agonist concentration tested; $\mathrm{pD}_{2}$ of the agonists was defined as the negative logarithm of the molar concentration of the agonist producing $50 \%$ of the maximal effect and was calculated from the concentration-response curves (Figure $3, A, C$, and $E$ ). Each experiment served as its own control. $E_{m a x}$, Efficacy; $d$, standardized effect size; $C I$, confidence interval; $p D_{2}$, potency. $* P<.05$, acidosis vs standard condition. $\dagger P<.01$, acidosis vs standard condition.

the arterial responsiveness to vasoconstrictors by way of the intracellular signaling pathways, mainly triggered by the $\alpha_{1 \mathrm{D}}$-adrenoceptor. However, we could not rule out that the size effects of acidosis made some of our results inconclusive. Thus, caution is needed before generalizing the present findings. Given that our experimental model was conducted with large conductance vessels, the results of our study must be seen at the functional level only, and extrapolating our data to clinical outcomes was beyond the scope of our study.

At least partially consistent with our results using whole human tissue, Huang and colleagues ${ }^{17}$ showed in a canine model that metabolic acidosis increased the peripheral vasoconstriction induced by epinephrine or norepinephrine. ${ }^{17}$ Furthermore, hypercapnic acidosis did not alter the vasoactive response to phenylephrine in large arterioles from rats. ${ }^{18}$ Acidosis seems to have an overall relaxant effect; however, this overall outcome does not reflect the influence of $\mathrm{H}^{+}$on each intracellular signaling pathway involved in the modulation of the vascular smooth muscle contraction. ${ }^{4}$ $\mathrm{H}^{+}$might interact with the voltage-dependent $\mathrm{Ca}^{2+}$ channels by inhibiting the influx of calcium ions across the cell membrane, with the adenosine triphosphate-sensitive $\mathrm{K}^{+}$ channels leading to membrane hyperpolarization and relaxation. ${ }^{19-21}$ In addition, both $\alpha_{1 \mathrm{~A}^{-}}$and $\alpha_{2}$-adrenoceptors interact with the voltage-dependent $\mathrm{Ca}^{2+}$ channels by changes in membrane polarization. ${ }^{22}$ We observed that acidosis enhances the responsiveness to methoxamine but not to phenylephrine. Unlike methoxamine, epinephrine and norepinephrine not only stimulate the $\alpha_{1}$ - and $\alpha_{2}$-adrenoceptors, but also the $\beta$-adrenoceptors, and phenylephrine is an equipotent agonist of $\alpha_{1 \mathrm{~A} / \mathrm{B}}$-adrenoceptors. ${ }^{16}$ Because methoxamine stimulates the $\alpha_{1 \mathrm{~A} / \mathrm{D}}$-adrenoceptors, our results strongly suggest that acidosis could increase the vasoactive response to vasoconstrictors mainly by sensitizing the $\alpha_{1 \mathrm{D}^{-}}$adrenoceptor. Thus, the standardized effect sizes also indicate that severe acidosis could increase the potency of epinephrine and decrease the potency of norepinephrine, suggesting more norepinephrine and less epinephrine would be required in cases of severe acidosis.

The reactivity of the human internal mammary artery graft to sympathomimetic drugs is mostly dependent on the $\alpha_{1 \mathrm{~A} / \mathrm{B} / \mathrm{D}^{-}}$and $\alpha_{2}$-adrenoceptors, because the internal mammary artery has a small number of $\beta$-adrenoceptors. ${ }^{14,23}$ The stimulation of $\alpha_{1}$-adrenoceptors activates phospholipase $\mathrm{C}$, which increases the inositol triphosphate intracellular concentration, stimulating $\mathrm{Ca}^{2+}$ release from the sarcoplasmic reticulum. ${ }^{24}$ In addition, the $\alpha_{1 \mathrm{~A}}$-adrenoceptor subtype indirectly activates the chloride channels, resulting in membrane depolarization that opens the voltage-dependent $\mathrm{Ca}^{2+}$ channels. ${ }^{22}$ At a greater concentration, the $\alpha_{1}$-adrenoceptors might also activate intracellular cyclic adenosine monophosphate. ${ }^{25}$ In contrast, the stimulation of $\alpha_{2 \mathrm{~A}}$-adrenoceptors closes the voltage-dependent $\mathrm{Ca}^{2+}$ channels and inhibits adenylate cyclase, leading to a decrease in intracellular cyclic adenosine monophosphate and an enhancement of $\mathrm{K}^{+}$efflux. ${ }^{26}$ We have established that acidosis does not significantly alter the arterial contraction dependent from the postjunctional $\alpha_{2}$-adrenoceptor stimulated by clonidine. However, the effect of acidosis on intracellular $\mathrm{Ca}^{2+}$ concentrations remains unclear, because the inositol triphosphate-induced increase in cytosolic free $\mathrm{Ca}^{2+}$ could be compensated for by a decreasing influx of $\mathrm{Ca}^{2+}$ across the cell membrane owing to inhibition of the voltage-dependent $\mathrm{Ca}^{2+}$ channels. Moreover, it has been shown that acidosis can increase or decrease the intracellular inositol triphosphate and cytosolic free $\mathrm{Ca}^{2+}$ concentrations, according to the cell type and species. ${ }^{24,27}$ 


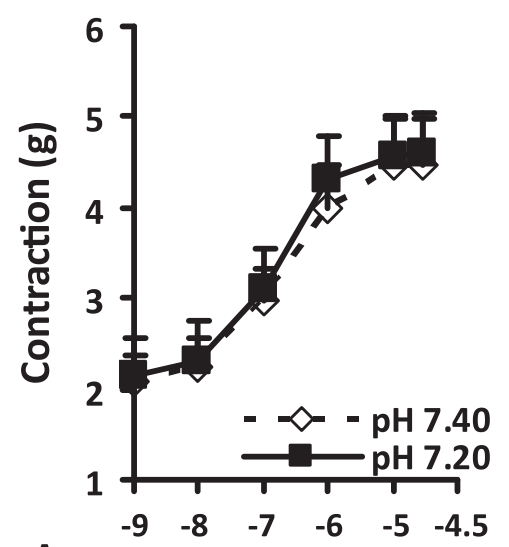

A Epinephrine $(\log M)$

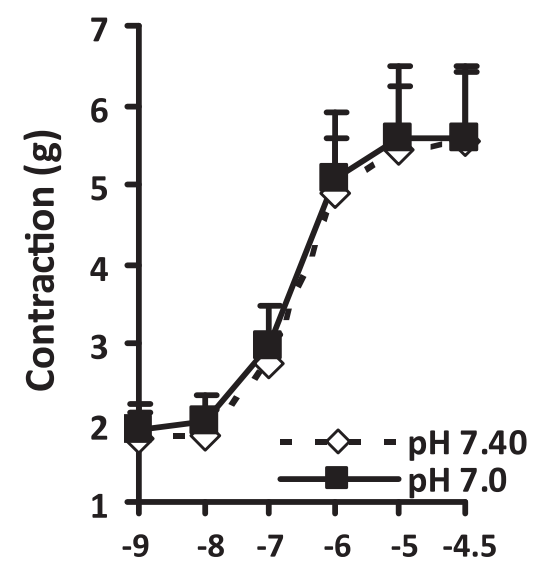

C Epinephrine $(\log M)$

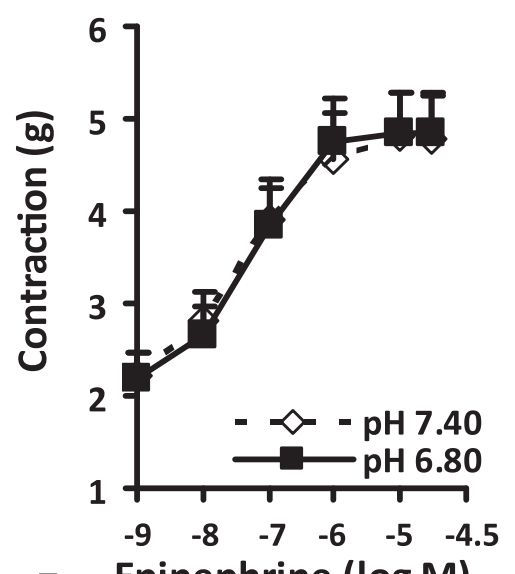

E Epinephrine $(\log M)$
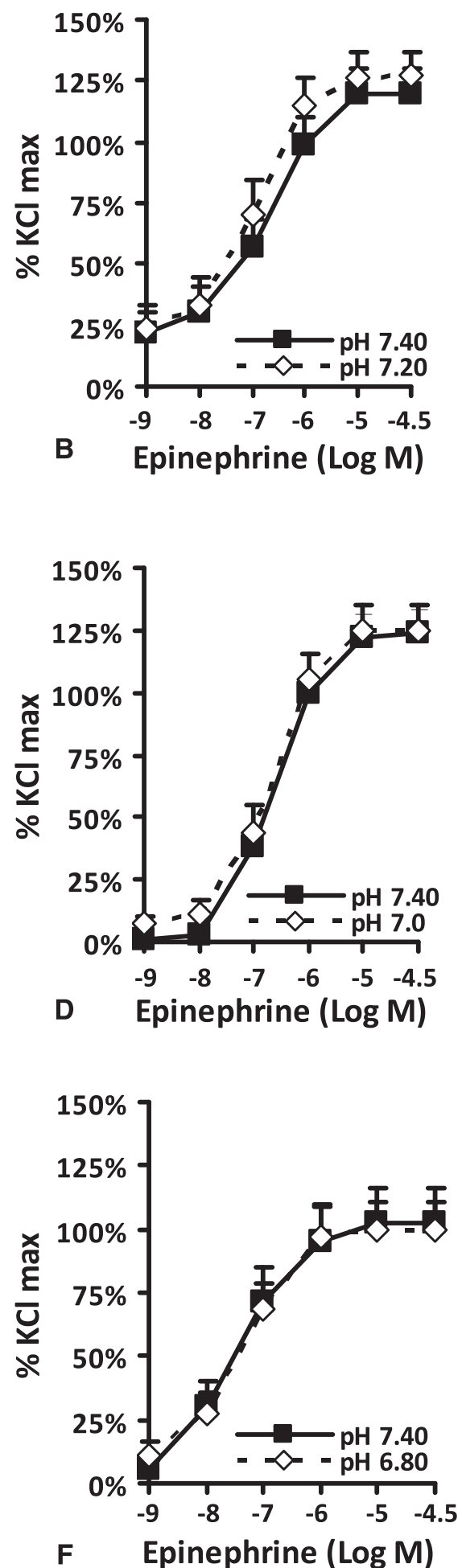

FIGURE 1. Concentration-response curves for epinephrine in human distal internal mammary arteries in absence (pH 7.40) and presence of extracellular acidosis: $\mathrm{A}$ and $\mathrm{B}, \mathrm{pH}$ of $7.20(\mathrm{n}=11)$; $\mathrm{C}$ and $\mathrm{D}, \mathrm{pH}$ of $7.0(\mathrm{n}=10)$; and $\mathrm{E}$ and F, pH of $6.8(\mathrm{n}=11)$. Contraction expressed in $g(\mathrm{~A}, \mathrm{C}$, and $\mathrm{E})$ and percentage of the maximal contraction induced by $90 \mathrm{mM} \mathrm{KCl}$ under standard conditions (pH 7.40; B, D, and F). Data presented as mean \pm standard deviation. Each experiment served as its own control. No differences between acidosis and the standard condition ( $\mathrm{pH} 7.40)$ were statistically significant $(P>.05$ for all). 


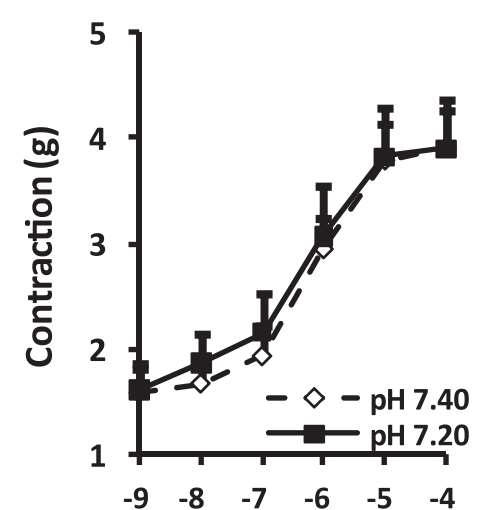

A Norepinephrine $(\log M)$

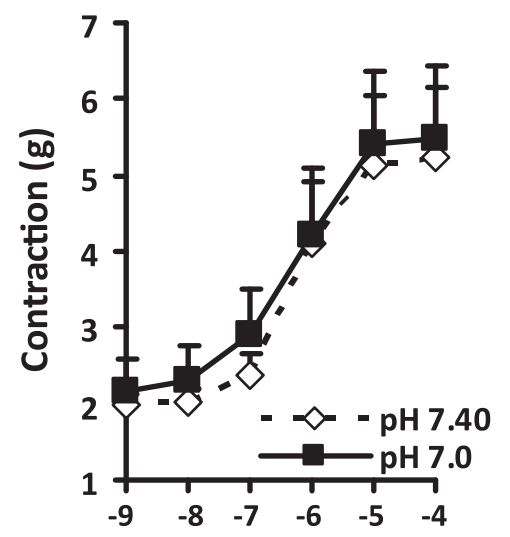

C Norepinephrine $(\log M)$

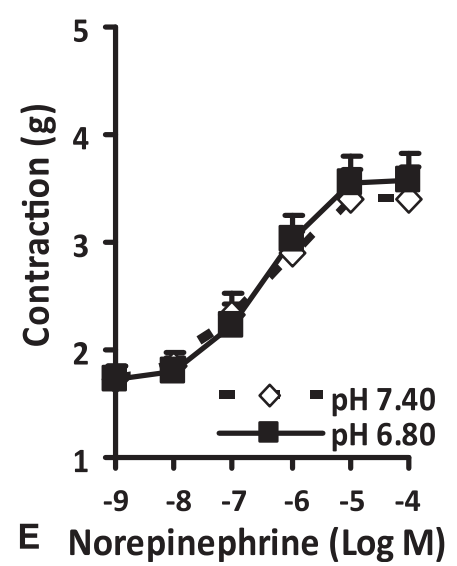

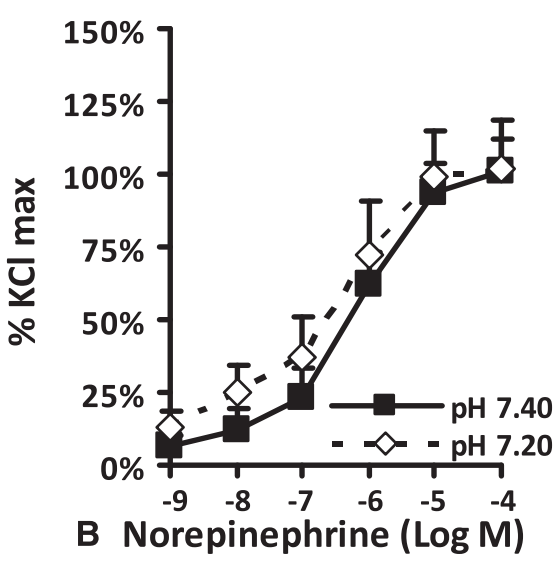
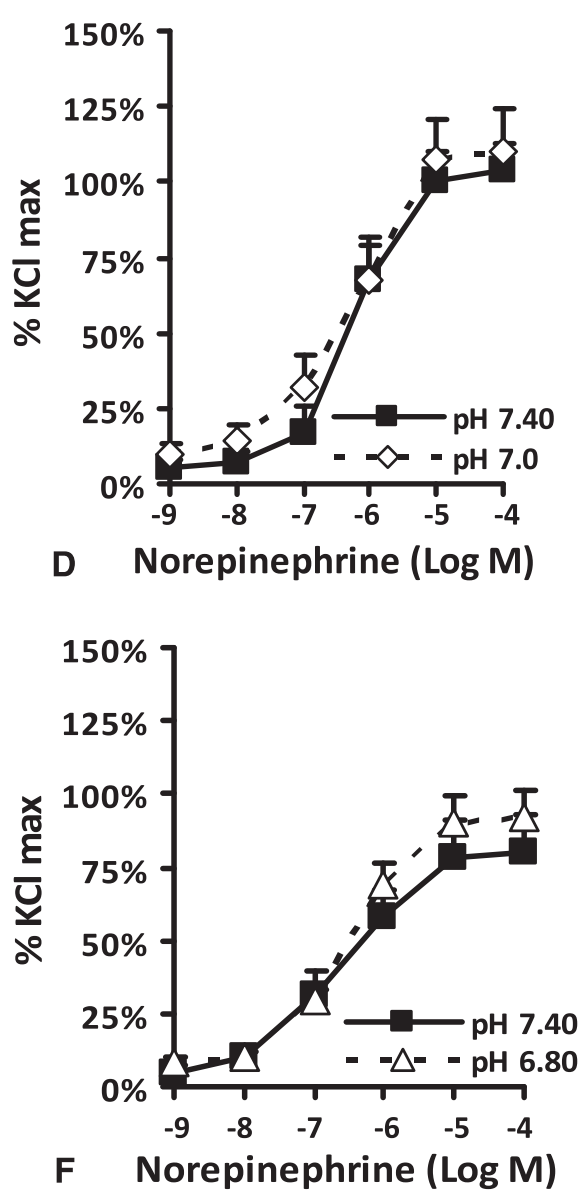

FIGURE 2. Concentration-response curves for norepinephrine in human distal internal mammary arteries in absence (pH 7.40) and presence of extracellular acidosis: $\mathrm{A}$ and $\mathrm{B}, \mathrm{pH}$ of $7.20(\mathrm{n}=11)$; $\mathrm{C}$ and $\mathrm{D}, \mathrm{pH}$ of $7.0(\mathrm{n}=10)$; and $\mathrm{E}$ and F, pH of $6.8(\mathrm{n}=11)$. Contraction expressed in $g(\mathrm{~A}, \mathrm{C}$, and E) and percentage of the maximal contraction induced by $90 \mathrm{mM} \mathrm{KCl}$ under standard conditions ( $\mathrm{pH} 7.40 ; \mathrm{B}, \mathrm{D}$, and F). Data presented as mean \pm standard deviation. Each experiment served as its own control. No differences between acidosis and the standard condition ( $\mathrm{pH} 7.40)$ were statistically significant $(P>.05$ for all).

In the present study, we observed that the real effect of acidosis on the arterial basal tone remained unpredictable. Arterial relaxation is mediated by endothelial nitric oxide, and nitric oxide production is reduced in the presence of human atherosclerosis. ${ }^{28} \beta$-Adrenergic dilation of the large arteries is also dependant on the vascular endothelium. ${ }^{29}$ Atherosclerosis can affect the internal mammary artery; however, surgical and experimental procedures can also damage the vascular endothelium. ${ }^{30}$ It has also been shown that extracellular acidosis causes endothelial 


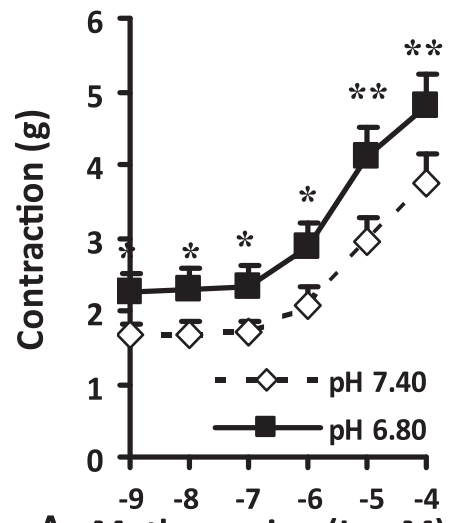

A Methoxamine (Log $M)$

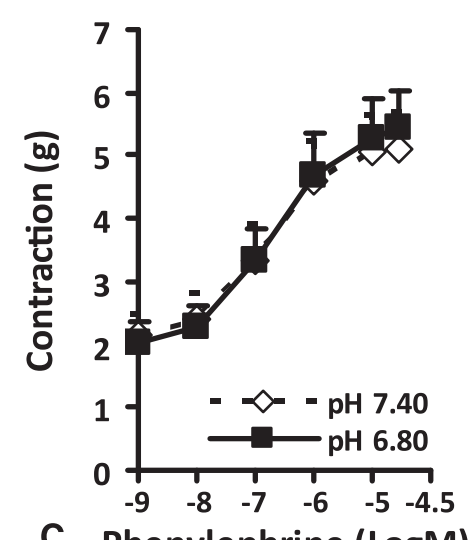

C Phenylephrine (LogM)

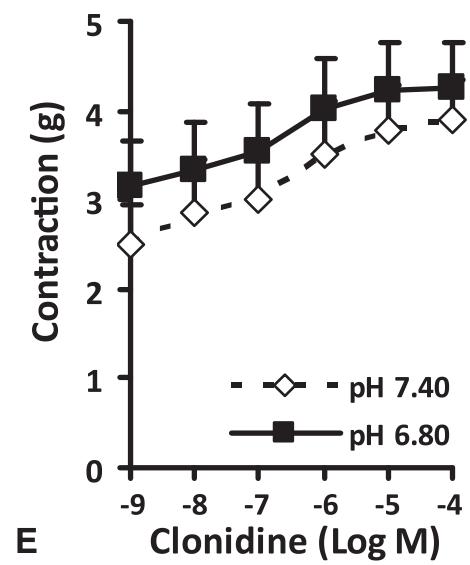

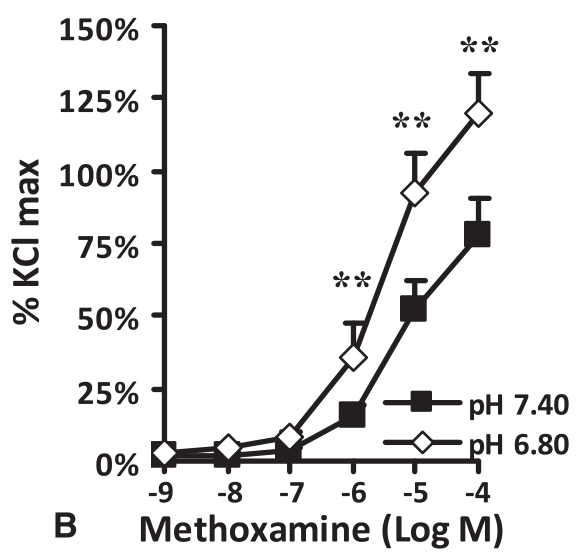
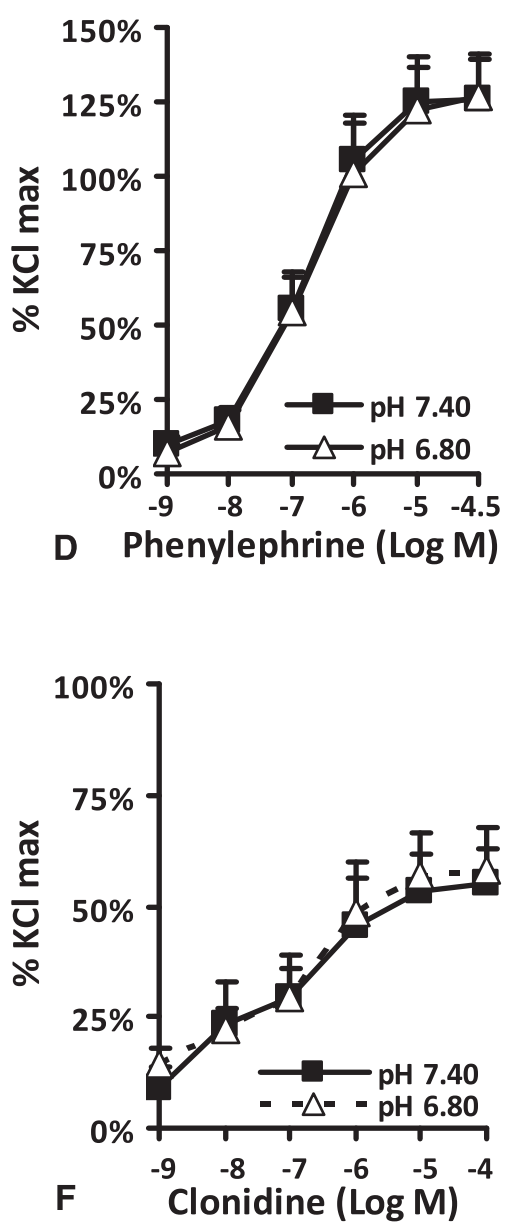

FIGURE 3. Concentration-response curves for ( $\mathrm{A}$ and $\mathrm{B}$ ) methoxamine, an $\alpha_{1 \mathrm{~A} / \mathrm{D}}$-adrenoceptor agonist $(\mathrm{n}=10)$; $\mathrm{C}$ and $\mathrm{D}$, phenylephrine, an equipotent agonist of $\alpha_{1 \mathrm{~A} / \mathrm{B}}$-adrenoceptors $(\mathrm{n}=10)$; and $(\mathrm{E}$ and $\mathrm{F})$ clonidine, a peripheral $\alpha_{2}$-adrenoceptor agonist $(\mathrm{n}=5)$, in human distal internal mammary arteries in the absence $(\mathrm{pH} 7.40)$ and presence $(\mathrm{pH}$ 6.80) of severe extracellular acidosis. Contraction expressed in $g(\mathrm{~A}, \mathrm{C}$, and $\mathrm{E})$ and percentage of the maximal contraction induced by $90 \mathrm{mM} \mathrm{KCl}$ under standard conditions ( $\mathrm{pH} 7.40$; B, D, and F). Acidosis sensitized human arterial rings to methoxamine but did not significantly alter the arterial responsiveness to phenylephrine and clonidine. Data presented as mean \pm standard deviation. Each experiment served as its own control. $* P<.05, * * P<.001$, acidosis vs standard condition $(\mathrm{pH} 7.40)$.

dysfunction by inhibiting store-operated $\mathrm{Ca}^{2+}$ entry and nitric oxide production in cultured porcine aortic endothelial cells. ${ }^{31}$ Taken together, these findings and our results suggest that acidosis could directly alter endothelium function in a $\mathrm{pH}$-dependent manner in human large vessels. 
The major limitation of the present study was the use of medium-size arteries, given that most systemic vascular resistance and control of tissue blood flow comes from the arteriolar resistance vessels. The ligand-receptor interactions could be different, depending on the tissue type. However, agonists such as epinephrine and norepinephrine will have the same dissociation constant, which is related to the affinity and potency of each agonist, for the same receptor, regardless of the tissue or cell. Another limitation of the present study was that the internal mammary artery is an $\alpha_{1}$ adrenoceptor-dominant artery with little $\alpha_{2^{-}}$or $\beta$-function. ${ }^{32}$ Finally, our findings should not be overinterpreted, because the present study focused mainly on the effect of severe acidosis on epinephrine and norepinephrine potency for the $\alpha_{1}$-adrenoceptor. Because potency is a measure of drug activity expressed in terms of the dose required to produce an effect of given intensity, our experimental model could have clinical relevance in perioperative management.

\section{CONCLUSIONS}

Severe extracellular acidosis did not influence the vasoactive properties of epinephrine and norepinephrine in human isolated mammary artery until a $\mathrm{pH}$ of 6.80 . From a pharmacologic viewpoint, the results of the present study could be an argument for not consistently increasing the doses of vasoconstrictors in the case of severe acidosis. From a clinical viewpoint, acidosis could affect the overall dynamic (eg, cardiac function, peripheral vasculature, coronary vasculature, and brain vasculature) in perioperative management. Thus, the question of whether to tolerate a lower $\mathrm{pH}$ in patients receiving vasoconstrictors requires future investigations based on the results of the present study to determine the best tolerance threshold of acidosis.

The authors thank the surgical nurses of the departments of cardiovascular surgery for their assistance during the collection of tissues.

\section{References}

1. Dellinger RP, Levy MM, Rhodes A, Annane D, Gerlach H, Opal SM, et al. Surviving sepsis campaign: international guidelines for the management of severe sepsis and septic shock: 2012. Crit Care Med. 2008;38:296-327.

2. Steenbergen C, Deleeuw G, Rich T, Williamson J. Effects of acidosis and ischemia on contractility and intracellular pH of rat heart. Circ Res. 1997;41: 849-58.

3. Overgaard CB, Dzavik V. Inotropes and vasopressors: review of physiology and clinical use in cardiovascular diseases. Circulation. 2008;118:1047-56.

4. Austin $\mathrm{C}$, Wray $\mathrm{S}$. Interaction between $\mathrm{Ca}^{2+}$ and $\mathrm{H}^{+}$and functional consequences in smooth muscle. Circ Res. 2000;86:355-63.

5. Nagai T, Anzai T, Kaneko H, Anzai A, Mano Y, Nagatomo Y, et al. Impact of systemic acidosis on the development of malignant ventricular arrhythmias after reperfusion therapy for ST-elevation myocardial infarction. Circ J. 2010;74: 1808-14.

6. Bellomo R, Ronco C. Continuous haemofiltration in the intensive care unit. Crit Care. 2000;4:339-45.

7. Jung B, Rimmele T, Le Goff C, Chanques G, Corne P, Jonquet O, et al. Severe metabolic or mixed acidemia on intensive care unit admission: incidence, prognosis and administration of buffer therapy. A prospective, multiple-center study. Crit Care. 2011;15:R238.
8. Cooper DJ, Herbetson MJ, Werner HA, Walley KR. Bicarbonates does not increase left ventricular contractility during L-lactic acidemia in pigs. Am Rev Respir Dis. 1993;148:317-22.

9. Hindman BJ. Sodium bicarbonate in the treatment of subtypes of acute lactic acidosis: physiologic considerations. Anesthesiology. 1990;72:1064-76.

10. Mulvany MJ, Halpern W. Contractile properties of small arterial resistance vessels in spontaneously hypertensive and normotensive rats. Circ Res. 1977;41: 19-26.

11. McPherson GA. Assessing vascular reactivity of arteries in the small vessel myograph. Clin Exp Pharmacol Physiol. 1992;19:815-25.

12. Stanke-Labesque F, Devillier P, Bedouch P, Cracowski JL, Chavanon O Bessard G. Angiotensin II-induced contractions in human internal mammary artery: effects of cyclooxygenase and lipoxygenase inhibition. Cardiovasc Res 2000; $47: 376-83$

13. Cohen J. A power primer. Psychol Bull. 1992;112:155-9.

14. Giessler C, Wangemann T, Silber RE, Dhein S, Brodde OE. Norepinephrineinduced contraction of human saphenous vein and human internal mammary artery: involvement of different alpha-adrenoceptor subtypes. Naunyn Schmiedebergs Arch Pharmacol. 2002;366:104-9.

15. Horie K, Obika K, Foglar R, Tsujimoto G. Selectivity of the imidazoline alpha adrenoceptor agonists (oxymetazoline and cirazoline) for human cloned alpha 1-adrenoceptor subtypes. Br J Pharmacol. 1995;116:1611-8.

16. Israilova M, Tanaka T, Suzuki F, Morishima S, Muramatsu I. Pharmacological characterization and cross talk of alpha1A- and alpha1B-adrenoceptors coexpressed in human embryonic kidney 293 cells. J Pharmacol Exp Ther. 2004; 309:259-66.

17. Huang YG, Wong KC, Yip WH, McJames SW, Pace NL. Cardiovascular responses to graded doses of three catecholamines during lactic and hydrochloric acidosis in dogs. Br J Anaesth. 1995;74:583-90.

18. McGillivray-Anderson KM, Jaber JE. Effect of acidosis on contraction of microvascular smooth muscle by $\alpha_{1}$ - and $\alpha_{2}$-adrenoceptors: implications for neural and metabolic regulation. Circ Res. 1990;66:1643-57.

19. Rohra DK, Sharif HM, Zubairi HS, Sarfraz K, Ghayur MN, Gilani AH. Acidosisinduced relaxation of human internal mammary artery is due to activation of ATP-sensitive potassium channels. Eur J Pharmacol. 2005;514:175-81.

20. Jackson WF. Ion channels and vascular tone. Hypertension. 2000;35:173-8.

21. Berger MG, Vandier C, Bonnet P, Jackson WF, Rusch NJ. Intracellular acidosis differentially regulates KV channels in coronary and pulmonary vascular muscle. Am J Physiol. 1998;275:H1351-9.

22. Mironneau J, Marcrez-Leprêtre N. Modulation of $\mathrm{Ca}^{2+}$ channels by alpha $1 \mathrm{~A}$ and alpha 2A-adrenoceptors in vascular myocytes: involvement of different transduction pathways. Cell Signal. 1995;5:471-9.

23. He GW, Buxton B, Rosenfeldt FL, Wilson AC, Angus JA. Weak betaadrenoceptor-mediated relaxation in the human internal mammary artery J Thorac Cardiovasc Surg. 1989;97:259-66.

24. Albuquerque ML, Leffler CW. pHo, pHi, and $\mathrm{PCO}_{2}$ in stimulation of $\mathrm{IP}_{3}$ and $[\mathrm{Ca} 2+] \mathrm{c}$ in piglet cerebrovascular smooth muscle. Proc Soc Exp Biol Med. 1998;219:226-34.

25. Evans BA, Broxton N, Merlin J, Sato M, Hutchinson DS, Christopoulos A, et al Quantification of functional selectivity at the human $\alpha(1 \mathrm{~A})$-adrenoceptor. $M o l$ Pharmacol. 2011;79:298-307.

26. Leprêtre N, Mironneau J, Morel JL. Both alpha 1A- and alpha 2A-adrenoceptor subtypes stimulate voltage-operated L-type calcium channels in rat portal vein myocytes: evidence for two distinct transduction pathways. J Biol Chem. 1994;269:29546-52.

27. Smith JB, Dwyer SD, Smith L. Lowering extracellular pH evokes inositol polyphosphate formation and calcium mobilization. J Biol Chem. 1989;264:8723-8.

28. Oemar BS, Tschudi MR, Godoy N, Brovkovich V, Lüscher TF. Reduced endothelial nitric oxide synthase expression and production in human atherosclerosis. Circulation. 1998;97:2494-8.

29. Ghaleh B, Béa ML, Dubois-Randé JL, Giudicelli JF, Hittinger L, Berdeaux A. Endothelial modulation of beta-adrenergic dilation of large coronary arteries in conscious dogs. Circulation. 1995;92:2627-35.

30. Kunze S, Jeschkeit-Schubbert S, Dahnken S, Fischer JH, Herzig S. Endothelial function after prolonged coronary artery oxygen persufflation in a rabbit model of heart preservation. Interact Cardiovasc Thorac Surg. 2002;1:16-22.

31. Asai M, Takeuchi K, Saotome M, Urushida T, Katoh H, Satoh H, et al. Extracellular acidosis suppresses endothelial function by inhibiting store-operated $\mathrm{Ca}^{2+}$ entry via non-selective cation channels. Cardiovasc Res. 2009;83:97-105.

32. He GW. Arterial grafts: clinical classification and pharmacological management Ann Cardiothorac Surg. 2013;2:507-18. 